\title{
Levels and profiles of Dechlorane Plus in a major E-waste dismantling area in China
}

\author{
Ke Xiao $\cdot$ Pu Wang $\cdot$ Haidong Zhang $\cdot$ \\ Hongtao Shang $\cdot$ Yingming $\mathrm{Li} \cdot$ Xinghong $\mathrm{Li} \cdot$ \\ Daiwei Ren · Weihai Chen · Qinghua Zhang
}

Received: 15 December 2012/ Accepted: 29 April 2013/Published online: 26 June 2013

(C) Springer Science+Business Media Dordrecht 2013

\begin{abstract}
Dechlorane Plus (DP) is a high-production volume, chlorinated flame retardant comprising two major isomers, syn- and anti-DP. In this study, levels of DP were measured in soil and earthworm samples in farmland from a typical E-waste dismantling area in China. The concentrations of total DP ranged from 0.17 to $1,990 \mathrm{ng} \mathrm{g}^{-1} \mathrm{dw}$ in soil samples and 3.43 to $89.2 \mathrm{ng} \mathrm{g}^{-1} \mathrm{lw}$ in earthworm samples. Higher DP levels were found in some main E-waste dismantling sites than those in other sites. The ratios of anti-DP to total DP $\left(f_{\text {anti }}\right)$ ranged from 0.57 to 0.80 in soil samples and 0.47 to 0.81 in earthworm samples, respectively. The $f_{\text {anti }}$ in most samples in this study was in the range of the reported technical DP values. These results showed that improper E-waste dismantling activities could result in the emission of DP. Most earthworm samples showed very low BSAFs (biota-to-soil accumulation factors) for total DP. The values of BSAF were in the range of $0.0007-1.85$, with an average value of 0.23 . This study presents the first report of the
\end{abstract}

Electronic supplementary material The online version of this article (doi:10.1007/s10653-013-9545-8) contains supplementary material, which is available to authorized users.

K. Xiao · P. Wang $\cdot$ H. Zhang $\cdot$ H. Shang .

Y. Li · X. Li · D. Ren · W. Chen · Q. Zhang $(\square)$

State Key Laboratory of Environmental Chemistry and Ecotoxicology, Research Center for Eco-

Environmental Sciences, Chinese Academy of Sciences,

P.O. Box 2871, Beijing 100085, China

e-mail: qhzhang@rcees.ac.cn
DP in earthworms, which would be useful for ecological risk assessment of DP in terrestrial ecosystem.

Keywords Dechlorane Plus · E-waste dismantling area $\cdot$ Soil $\cdot$ Earthworm $\cdot$ BSAF $\cdot$ Chlorinated flame retardant

\section{Introduction}

The use of flame retardants has grown dramatically over the past 30 years as the fire safety regulations grow stricter. But some flame retardants exhibit the characteristics of persistence, bioaccumulative potential, toxicities and potential health risks to the human population (Birnbaum and Staskal 2004; de Wit 2002). These harmful compounds have faced governmental regulations and have been replaced by nonregulated ones. For instance, Dechlorane Plus (DP) is an unregulated chlorinated flame retardant, first introduced into the market by Hooker Chemical in the 1960s as a substitute for Dechlorane (Mirex) $\left(\mathrm{C}_{10} \mathrm{Cl}_{12}\right.$, CAS No. 2385-85-5) banned for its toxicity (Kaiser 1978). DP was primarily used in products such as electrical wires and cables, plastic roofing materials, and hard connectors in computers and televisions (Qiu et al. 2007). Commercial DP comprises two stereoisomers (syn- and anti-) that occur in a ratio between 1:2 and 1:3 (Tomy et al. 2007). DP has been manufactured by Oxychem in North America for more than 40 years. In China, another DP production facility was also 
identified recently (Wang et al. 2010b). With an annual world production of about 500-5,000 tons, DP was classified as a high-production volume (HPV) compound in the United States (Gauthier and Letcher 2009). Although DP has been produced and used for decades, it has not cause much concern until recently (Hoh et al. 2006). Evidence suggested that DP may be a worldwide contaminant, and it has been detected in various environmental media and biota samples such as air (Hoh et al. 2006; Ma et al. 2011; Moller et al. 2010; Ren et al. 2008), soil (Ma et al. 2011; Wang et al. 2010a; Yu et al. 2010), sediment (Qi et al. 2010), water (Moller et al. 2010; Qi et al. 2010), indoor dust (Zhu et al. 2007; Ren et al. 2010), fish (Shen et al. 2011), dolphin (de la Torre et al. 2012), birds (Gauthier et al. 2009; Guerra et al. 2011) and humans (Ren et al. 2009) in the past few years. These data indicate that DP is a global pollutant and exhibited POPs (persistent organic pollutants) characteristics: persistent, potential bioaccumulation and subject to long-range transport. So, it is reasonable to consider that DP may be candidates for Annex D evaluation under the United Nations Stockholm Convention on persistent organic pollutants (POPs), as a recently review suggested (Sverko et al. 2011). Therefore, it is necessary to better understand their emissions, levels, exposures and potential impact in biota. More monitoring and bioaccumulation information are needed.

In China, there are two significant emission sources for DP: One is the DP manufacturing factory in Huai' an city, Jiangsu province, as mentioned above. This factory has short production history and started to produce DP since 2005 (Wang et al. 2010b). Another emission source is E-waste. There are three major E-waste dismantling areas in China: Taizhou city in Zhejiang province, Qingyuan and Guiyu town in Guangdong province. Previous study has found relatively higher DP levels in the surface soils of Guiyu and Qingyuan (Yu et al. 2010). However, the information on DP in Taizhou remains unclear and very little data are available for DP concentrations in Taizhou in recent years. Actually, more than 2 million tons of E-wastes were dismantled in Taizhou every year to recycle metals such as copper and aluminum (Han et al. 2009). It is thus important to know contamination status of DP in Taizhou because the types of the wastes dismantled in Taizhou are somehow different from those in Guiyu and Qingyuan (Han et al. 2009).
It is well known that soil acts as a major sink for POPs in the environment (Jones and de Voogt 1999). However, the total concentrations of POPs are not necessarily indicative of the toxicity of the soil because sequestered POPs are not bioavailable and provide minimal environmental risk. So, it is essential to know the bioavailability of POPs in soil and their bioaccumulation potential in terrestrial food webs. Earthworms are commonly used as an important link in transporting environmental contaminants from soil to other organisms in terrestrial food webs. This is because earthworms, as the most common animal found in soil, can process large amounts of soil and assimilate a part of organic matter it contains and are frequently consumed by vertebrate organisms such as bird and some small mammals. They are ideal testing organisms for the bioaccumulation of pollutants in soil (Jager et al. 2003). So, in this paper, DP levels and isomer profiles both in agricultural soils and in earthworms from Taizhou area are presented. The bioaccumulation of DP in earthworms is also discussed. To our knowledge, this is the first study to report the detection of DP levels in earthworms that live at the bottom of the food web.

\section{Materials and methods}

All solvents and reagents used were of analytical or pesticide grade. Silica was purchased from Merck (Germany). Basic alumina was obtained from Aldrich (USA). Calibration standard solutions (syn-DP and anti-DP), ${ }^{13} \mathrm{C}_{12}$-labeled surrogate standard $\left({ }^{13} \mathrm{C}_{12}\right.$ labeled $\mathrm{PCB}-209)$ and ${ }^{13} \mathrm{C}_{12}$-labeled injection standard $\left({ }^{13} \mathrm{C}_{12}\right.$-labeled PCB-194) were purchased from Wellington Laboratories (Canada).

Fifteen agricultural soil samples and fifteen composite earthworm samples in this study were collected in September 2009 in farmlands around Luqiao District, Taizhou, an E-waste dismantling area in the southeast coastline of China. The sampling sites were shown in Fig. s1, in which there are four typical E-waste dismantling sites that include Baifengao (BFA, site 6), Tingyu (TiY, site 7), Fengjiang (FJ, site 8) and Tongyu (ToY, site 4).The individual earthworm samples were grouped according to sites. In each site, up to forty individual earthworm samples were obtained using stainless steel spade and pickax and pooled into one pooled sample. As a result, 15 pooled samples were 
created. Each agricultural soil sample was sampled from the same sites as earthworm samples. The soil sample was obtained compositely using a precleaned stainless steel shovel and was packed in aluminum foil. Earthworms were depurated for about $48 \mathrm{~h}$ and then rinsed with pure water to remove all adhered particles. After sample collection, all samples were stored at $-20{ }^{\circ} \mathrm{C}$ until further analysis.

The soil and earthworm samples were spiked with 1 ng PCB 209 as surrogate standard prior to extraction. The spiked samples were extracted using ASE (ASE 300, Dionex) with organic solvents (hexane:dichloromethane $=1: 1 \mathrm{v} / \mathrm{v})$. The extracts were concentrated by a rotary evaporator (Heidolph) and followed by a cleanup with multilayer silica columns and basic alumina columns. The final extracts were spiked with $1 \mathrm{ng}{ }^{13} \mathrm{C}_{12}$-labeled injection standards of PCB-194 for recovery quantification.

The sample extracts were analyzed on the DFS High Resolution GC/MS system coupled to a TRACE GC (Thermo Scientific DFS). Chromatographic separation was achieved with a DB-5MS fused-silica capillary column (J\&W Scientific, $15 \mathrm{~m}, 0.25 \mathrm{~mm}$ ID, $0.1 \mu \mathrm{m}$ film thickness).A $1 \mu \mathrm{L}$ sample was introduced into the injection port working in splitless mode at $250{ }^{\circ} \mathrm{C}$. The $\mathrm{GC}$ oven ramping temperature program was as follows: initial $80{ }^{\circ} \mathrm{C}$ for $1.0 \mathrm{~min}, 10^{\circ} \mathrm{C} / \mathrm{min}$ until $320^{\circ} \mathrm{C}$ and hold for a final $5.0 \mathrm{~min}$. The HRMS system was operated in EI positive mode with electron energy of $45 \mathrm{eV}$. The mass transfer line and ion source temperature was $270{ }^{\circ} \mathrm{C}$. Selected ion monitoring (SIM) mode was used with a resolution of more than 10000. Concentrations of DP in soil samples were determined by monitoring abundant ions of the fragment cluster at $\mathrm{m} / \mathrm{z} 271.8102 / 273.8072$ for synand anti-DP, with the ions $\mathrm{m} / \mathrm{z}$ 651.7142/653.7113 for identification.

One laboratory blank sample was analyzed for quality control. The result showed that blank did not contain any detectable DP. The retention times of sample peaks matched those of the standard compounds within $0.1 \mathrm{~min}$. Peak areas were within $15 \%$ of the corresponding theoretical isotopic ratios. All samples were spiked with a surrogate recovery standard $\left({ }^{13} \mathrm{C}\right.$-labeled $\left.\mathrm{PCB}-209\right)$. The recovery of labeled compound of labeled PCB-209 ranged from 76 to $113 \%$.

Biota-to-soil accumulation factors (BSAFs) are widely used to estimate the degree of exposure and the potential risk in wildlife based on levels of soil contamination.

The BSAF is defined (Ankley et al. 1992) as

$\mathrm{BSAF}=\left(C_{\mathrm{o}} / f_{1}\right) /\left(C_{\mathrm{s}} / f_{\mathrm{soc}}\right)$

where $C_{\mathrm{o}}$ is the chemical concentrations in the organism, $f_{1}$ is the lipid fraction of the organism, $C_{\mathrm{s}}$ is the corresponding chemical concentration in surficial soil, and $f_{\text {soc }}$ is the fraction of soils as organic carbon.

\section{Results and discussion}

The total DP (sum of the syn- and anti-isomers) in both soil and earthworm samples and the TOC in soil samples were presented in Table 1. DP was detected in all of the soil and earthworm samples. The concentrations varied to a great extent in soil samples at different sampling sites, with the total DP values ranging from 0.17 to $1,990 \mathrm{ng} \mathrm{g}^{-1}$ dry wt (median; $19.7 \mathrm{ng} \mathrm{g}^{-1}$ dry wt). No correlations were found between the level of DP and TOC. There are several studies on the levels of DP in soils in China and Japan which are summarized and presented in Table s1. It showed that the typical DP levels were $0.1-1 \mathrm{ng} / \mathrm{g} \mathrm{dw}$ at rural locations and about $5 \mathrm{ng} / \mathrm{g} \mathrm{dw}$ in urban areas,

Table 1 Total DP concentrations in soil and earthworm samples

\begin{tabular}{llll}
\hline Site & TOC $(\%)$ & $\begin{array}{l}\text { Soils (ng/g } \\
\text { dry weight) }\end{array}$ & $\begin{array}{l}\text { Earthworms } \\
\text { (ng/g lipid weight) }\end{array}$ \\
\hline BFA & 2.70 & 0.713 & 21.1 \\
FJ & 3.44 & 917 & 89.2 \\
GQ & 1.79 & 14.3 & 3.43 \\
HoJ & 2.21 & 46.8 & 8.39 \\
JQ & 2.00 & 718 & 31.4 \\
LY & 2.15 & 42.3 & 8.41 \\
PJ & 2.20 & 1,990 & 62.9 \\
SJ & 2.32 & 15.6 & 87.8 \\
SB & 3.51 & 19.7 & 29.8 \\
TiY & 2.54 & 5.16 & 45.4 \\
Toy & 2.54 & 1.74 & 20.4 \\
TT & 0.77 & 0.174 & 33.4 \\
XC1 & 1.81 & 352 & 18.3 \\
XC2 & 1.73 & 45.7 & 14.9 \\
ZG & 1.75 & 3.99 & 27.6 \\
\hline
\end{tabular}


respectively, in China (Yu et al. 2010; Ma et al. 2011; Wang et al. 2010a). Total DP concentrations in most soil samples in this study were found to be higher than those reported in urban areas in China. The highest total DP concentration of 1,990 ng/g dry wt found in soil samples in this study was more than the highest level found in Huai' an area $(1,200 \mathrm{ng} / \mathrm{g})$ and Gui $\mathrm{Yu}$ area $(21.2 \mathrm{ng} / \mathrm{g})$, but less than the highest level found in Qingyuan area (3,327 ng/g) (Ma et al. 2011b; Wang et al. 2010a; Yu et al. 2010). The two highest concentrations of total DP were found in soils from the two main E-waste recycling sites of FJ (site 8) and PJ (site 14). Though Baifengao (BFA, site 6) and Tingyu (TiY, site 7) are also two other main E-waste dismantling sites, the DP levels in the both sites were relatively low. No correlation was found between the values of DP and TOC $\left(R^{2}<0.5, p>0.05\right)$. The concentration and distribution of contaminants in environment are closely connected with natural processes and human activities. The levels of DP in agriculture soils might be affected after being released into the environment by human activities such as irrigation and cultivation. This might explain why the levels of DP were not quite high as expected in some main dismantling sites such as 6(BFA) and 7(TiY) and some areas with high TOC such as $3(\mathrm{SB})$.

In earthworm samples, the total DP values ranged from 3.43 to $89.2 \mathrm{ng} / \mathrm{g}$ lw (median $27.6 \mathrm{ng} / \mathrm{g} \mathrm{lw}$ ). These levels are not strongly correlated with the corresponding levels in soil samples. The earthworm samples from the sites of FJ (site 8) and PJ (site 14) have the second highest and the third highest level of DP, respectively, rather than the highest level. The highest level of DP was found in SJ (site 11). However, soils are a super-heterogeneous environmental matrix with varying organic carbon, $\mathrm{pH}$ and particle size distribution. The levels of contaminant in earthworms can be dramatically affected by these soil physical/chemical characteristics as well as by physiology and behavior of the earthworms (Lanno et al. 2004). So, the distribution of DP in earthworms may not be complete with the DP distribution in the soils.

This is the first study reporting DP concentrations in earthworm samples, so there are currently no data available for the comparison of DP in earthworm. These results reconfirmed the previous findings that improper E-waste dismantling activities could result in the emission of DP (Yu et al. 2010) and demonstrate that earthworms in agricultural soils could absorb DP from soils.

Technical DP is composed of syn-DP isomer and anti-DP isomer. The fraction of anti-DP in total DP $\left(f_{\text {anti }}\right)$ or the fraction of syn-DP in total DP $\left(f_{\text {syn }}\right)$, or the ratio of syn- to anti-isomers is generally used when discussing the environmental transportation and fate of the two structural isomers. In this study, $f_{\text {anti }}$ was calculated as the concentration of anti-DP divided by the sum of the concentrations of anti- and syn-DP. Figure 1 shows the values of the fraction of antiisomer $\left(f_{\text {anti }}\right)$ in soil and earthworm samples at different sites.

The result shows that concentrations of anti-DP isomer were consistently greater than those of syn-DP isomer concentrations in all soil samples and most earthworm samples. The values of $f_{\text {anti }}$ were in the range of $0.57-0.80$ (median 0.74 ) and the mean was 0.71 in soil samples. In earthworm samples, the values of $f_{\text {anti }}$ were in the range of $0.47-0.81$ (median 0.71 ) with the mean of 0.70 . It was reported previously that the values of $f_{\text {anti }}$ of the technical DP were between 0.64 and 0.80 (Hoh et al. 2006; Qiu et al. 2007; Sverko et al. 2008; Tomy et al. 2007; Zhu et al.2008). The $f_{\text {anti }}$ in most soil samples and earthworm samples in this study were in the range of the reported technical DP values. It was reported in the previous findings that biota exhibited species-specific stereoselective enrichment of either syn- or anti-DP (Sun et al. 2012). For example, the chemical structure of the anti-DP isomer should be more susceptible to biological attack than the less sterically hindered syn-DP isomer, which may lead to the rise of $f_{\text {syn }}$ and the decline of the $f_{\text {anti }}$ in biological samples compared to the value of technical DP. In this study, the values of $f_{\text {anti }}$ in two-thirds of the earthworm samples are lower than those in soil samples collected from the same site, being consistent with some previous statements. However, it can be seen from the Fig. 1 the $f_{\text {anti }}$ values in some earthworm samples are higher than those in the soil samples collected from the same site such as BFA, Toy, XC1, $\mathrm{XC} 2$, SJ. As mentioned earlier in this article, various abiotic and biotic modifying factors may affect the bioavailability of the earthworm. That may be contributed to the difference of the results.

The calculated BSAF values for syn-DP, anti-DP and total DP in the earthworm samples were shown in Fig. s2. Earthworm showed very low BSAFs for total $\mathrm{DP}$ in most samples. The values of BSAF were in the 
Fig. $1 f_{\text {anti }}$ values for soils and earthworms. The solid lines indicate the range of the $f_{\text {anti }}$ values of the commercial product (0.64-0.80)

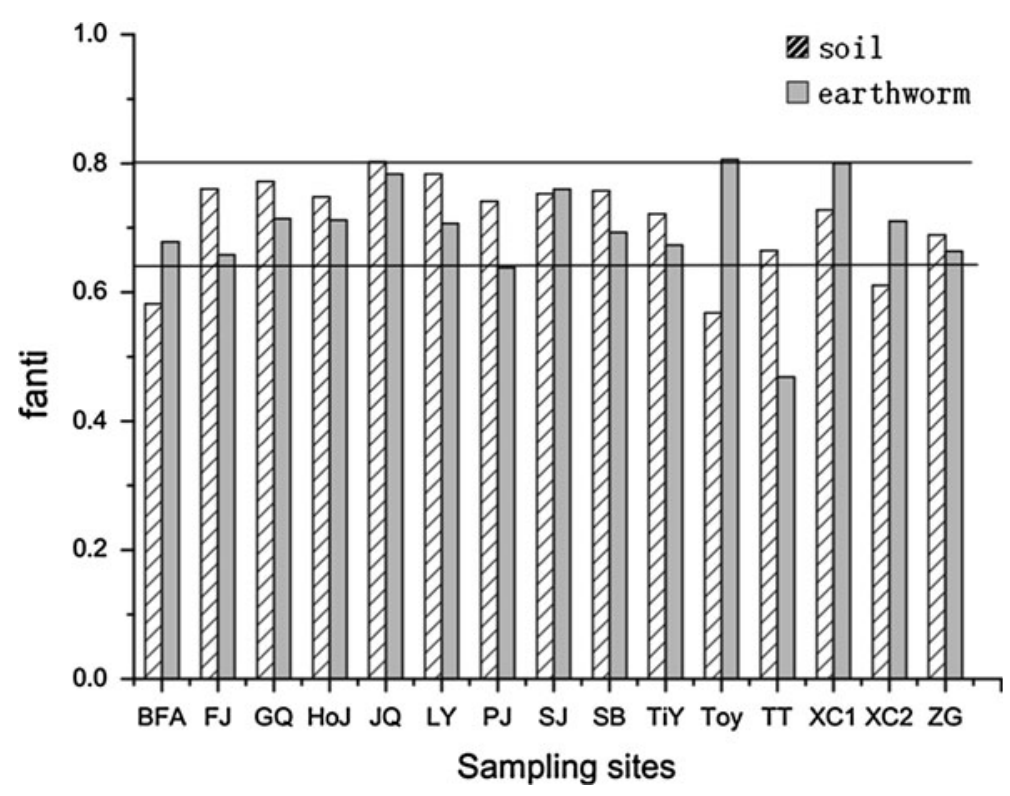

range of $0.0007-1.85$ (median 0.006), with average value of 0.23 . The values were less than 0.01 in eight samples (about $53 \%$ ) and between 0.05 and 1 in six samples $(40 \%)$, respectively. Only one value was larger than 1 . The site TT has the highest BSAF value of DP 1.85 even the total DP was the lowest, thereby suggesting that the earthworm there might have a relatively high bioavailability.

It was generally reported that soil organic matter plays the most important role in POPs sorption and bioavailability (Amorim et al. 2002). In this study, no correlation was found between the values of BSAF and TOC $\left(R^{2}<0.5, p>0.05\right)$. Actually, according to Vlčková et al. (Vlcková and Hofman 2012), TOC content may not be the most important factor affecting the bioavailability of POPs in soils with low or middle TOC content (arable and grassland soils). Considering that DP exhibits POPs characteristics, this might explain the result in this study. The value of TOC in site TT is the lowest compared with other sites and a little difference was found in soil type between TT and the other places, which might contribute to a relatively high BSAF value in TT. Actually, the bioavailability of DP was affected by many factors, and it was hard to determine what the most important reason caused the result. Deeper investigation was needed to better understand the bioavailability of DP.

According to the Fig. s2, the values of BSAF for synDP were observed a little higher than those for the anti- isomer in two-thirds of the samples. To some extent, the result in this study is in agreement with previous research, but further research is required. It was reported that higher BSAFs for syn-DP compared to anti-DP were found in fish samples (Zhang et al. 2011).This might attribute to the differences in physiochemical properties (such as $K_{\mathrm{OW}}$ and the stereo structure conformation) between the two DP isomers (Zhang et al. 2011).

According to Zhang et al. (2011), very low BSAFs for total DP (with average values of 0.004, 0.025 and 0.003 ) were found in fish. Actually, these values are much less than those obtained from the equilibrium partitioning theory, according to which BSAFs for the hydrophobic organic chemicals should be 1-2 (Burkhard et al. 2004). Several factors such as nonequilibrium conditions and chemical metabolism may contribute to the low BSAF values. In this study, the same low or even lower BSAF values were also observed in the most earthworm samples, which may be due to the similar reasons as mentioned above. Further research should be carried out to clarify the biodegradation of DP isomers in earthworms and their abiotic transformation in environment.

\section{Conclusion}

In summary, the results in this study provided an obvious evidence for DP contamination in E-waste 
dismantling areas. Though very low BSAF values were observed in most earthworm samples, ecological and health risk assessments should be carried out around E-waste dismantling area because of potentially high environmental concentrations of DP. There are many factors affecting the bioavailability of DP in environment. Further research about both abiotic and biotic transformations of DP should be also performed in order to conduct a full risk assessment of DP in terrestrial ecosystem.

Acknowledgments This work was supported by National Natural Science Foundation of China (No21107122, No21107121 and No21177152).

\section{References}

Amorim, M. J., Paulo Sousa, J., Nogueira, A. J. A., \& Soares, A. M. V. M. (2002). Bio-accumulation and elimination of 14C-lindane by Enchytraeus albidusin artificial (OECD) and a natural soil. Chemosphere, 49(3), 323-329.

Ankley, G. T., Cook, P. M., Carlson, A. R., Call, D. J., Swenson, J. A., Corcoran, H. F., et al. (1992). Bioaccumulation of Pcbs from sediments by oligochaetes and fishes-comparison of laboratory and field studies. Canadian Journal of Fisheries and Aquatic Sciences, 49(10), 2080-2085.

Birnbaum, L. S., \& Staskal, D. F. (2004). Brominated flame retardants: Cause for concern? Environmental Health Perspectives, 112(1), 9-17.

Burkhard, L. P., Cook, P. M., \& Lukasewycz, M. T. (2004). Biota-sediment accumulation factors forpolychlorinated biphenyls, dibenzo-p-dioxins, and dibenzofurans in southern Lake Michigan lake trout (Salvelinus namaycush). Environmental Science and Technology, 38, 5297-5305.

de la Torre, A., Alonso, M. B., Martinez, M. A., Sanz, P., Shen, L., Reiner, E. J., et al. (2012). Dechlorane-related compounds in franciscana dolphin (Pontoporia blainvillei) from Southeastern and Southern Coast of Brazil. Environmental Science and Technology, 46(22), 12364-12372.

de Wit, C. A. (2002). An overview of brominated flame retardants in the environment. Chemosphere, 46(5), 583-624.

Gauthier, L. T., \& Letcher, R. J. (2009). Isomers of dechlorane plus flame retardant in the eggs of herring gulls (Larus argentatus) from the Laurentian Great Lakes of North America: Temporal changes and spatial distribution. Chemosphere, 75(1), 115-120.

Guerra, P., Fernie, K., Jimenez, B., Pacepavicius, G., Shen, L., Reiner, E., et al. (2011). Dechlorane plus and related compounds in Peregrine Falcon (Falco peregrinus) eggs from Canada and Spain. Environmental Science and Technology, 45(4), 1284-1290.

Han, W. L., Feng, J. L., Gu, Z. P., Chen, D. H., Wu, M. H., \& Fu, J. M. (2009). Polybrominated diphenyl ethers in the atmosphere of Taizhou, a major e-waste dismantling area in China. Bulletin of Environmental Contamination and Toxicology, 83(6), 783-788.
Hoh, E., Zhu, L., \& Hites, R. A. (2006). Dechlorane plus, a chlorinated flame retardant, in the Great Lakes. Environmental Science and Technology, 40(4), 1184-1189.

Jager, T., Fleuren, R. H. L. J., Hogendoorn, E. A., \& De Korte, G. (2003). Elucidating the routes of exposure for organic chemicals in the earthworm, Eisenia andrei (Oligochaeta). Environmental Science and Technology, 37(15), 3399-3404.

Jones, K. C., \& de Voogt, P. (1999). Persistent organic pollutants (POPs): State of the science. Environmental Pollution, 100(1-3), 209-221.

Kaiser, K. L. E. (1978). Rise and fall of mirex. Environmental Science and Technology, 12(5), 520-528.

Lanno, R., Wells, J., Conder, J., Bradham, K., \& Basta, N. (2004). The bioavailability of chemicals in soil for earthworms. Ecotoxicology and Environmental Safety, 57(1), 39-47.

Ma, W. L., Liu, L. Y., Qi, H., Sun, D. Z., Shen, J. M., Wang, D. G., et al. (2011). Dechlorane plus in multimedia in northeastern Chinese urban region. Environment International, $37(1), 66-70$.

Moller, A., Xie, Z., Sturm, R., \& Ebinghaus, R. (2010). Largescale distribution of dechlorane plus in air and seawater from the Arctic to Antarctica. Environmental Science and Technology, 44(23), 8977-8982.

Qi, H., Liu, L., Jia, H., Li, Y. F., Ren, N. Q., You, H., et al. (2010). Dechlorane Plus in surficial water and sediment in a northeastern Chinese river. Environmental Science and Technology, 44(7), 2305-2308.

Qiu, X., Marvin, C. H., \& Hites, R. A. (2007). Dechlorane plus and other flame retardants in a sediment core from Lake Ontario. Environmental Science and Technology, 41(17), 6014-6019.

Ren, N. Q., Sverko, E., Li, Y. F., Zhang, Z., Harner, T., Wang, D. G., et al. (2008). Levels and isomer profiles of Dechlorane Plus in Chinese air. Environmental Science and Technology, 42(17), 6476-6480.

Ren, G. F., Yu, Z. Q., Ma, S. T., Chen, L. G., Luo, X. F., Sheng, G. Y., et al. (2010). Dechlorane Plus in in-and outdoor air of an urban city in southern China. Organohalogen Compounds, 72, 852-855.

Ren, G. F., Yu, Z. Q., Ma, S. T., Li, H. R., Peng, P. G., Sheng, G. Y., et al. (2009). Determination of Dechlorane plus in serum from electronics dismantling workers in South China. Environmental Science and Technology, 43(24), 9453-9457.

Shen, L., Reiner, E. J., Helm, P. A., Marvin, C. H., Hill, B., Zhang, X. M., et al. (2011). Historic trends of Dechloranes $602,603,604$, Dechlorane plus and other norbornene derivatives and their bioaccumulation potential in lake Ontario. Environmental Science and Technology, 45(8), 3333-3340.

Sun, Y. X., Luo, X. J., Wu, J. P., Chen, S. J., Zhang, Q., et al. (2012). Species- and tissue-specific accumulation of Dechlorane Plus in three terrestrial passerine bird species from the Pearl River Delta, South China. Chemosphere, 89(4), 445-451.

Sverko, E., Tomy, G. T., Marvin, C. H., Zaruk, D., Reiner, E., Helm, P. A., et al. (2008). Dechlorane plus levels in sediment of the lower Great Lakes. Environmental Science and Technology, 42(2), 361-366.

Sverko, E., Tomy, G. T., Reiner, E. J., Li, Y. F., McCarry, B. E., Arnot, J. A., et al. (2011). Dechlorane plus and related 
compounds in the environment: A review. Environmental Science and Technology, 45(12), 5088-5098.

Tomy, G. T., Pleskach, K., Ismail, N., Whittle, D. M., Helm, P. A., Sverko, E., et al. (2007). Isomers of dechlorane plus in Lake Winnipeg and Lake Ontario food webs. Environmental Science and Technology, 41(7), 2249-2254.

Vlčková, K., \& Hofman, J. (2012). A comparison of POPs bioaccumulation in Eisenia fetida in natural and artificial soils and the effects of aging. Environment Pollution, 160(1), 49-56.

Wang, B., Iino, F., Huang, J., Lu, Y., Yu, G., \& Morita, M. (2010a). Dechlorane Plus pollution and inventory in soil of Huai' an City China. Chemosphere, 80(11), 1285-1290.

Wang, D. G., Yang, M., Qi, H., Sverko, E., Ma, W. L., Li, Y. F., et al. (2010b). An Asia-specific source of dechlorane plus: Concentration, isomer profiles, and other related compounds. Environmental Science and Technology, 44(17), 6608-6613.

Yu, Z., Lu, S., Gao, S., Wang, J., Li, H., Zeng, X., et al. (2010). Levels and isomer profiles of Dechlorane Plus in the surface soils from e-waste recycling areas and industrial areas in South China. Environmental Pollution, 158(9), 2920-2925.

Zhang, Y., Wu, J. P., Luo, X. J., Sun, Y. X., Mo, L., Chen, S. J., et al. (2011). Biota-sediment accumulation factors for Dechlorane Plus in bottom fish from an electronic waste recycling site, South China. Environment International, 37(8), 1357-1361.

Zhu, J., Feng, Y. L., \& Shoeib, M. (2007). Detection of dechlorane plus in residential indoor dust in the city of Ottawa, Canada. Environmental Science \& Technology, 41(22), 7694-7698.

Zhu, J. P., Hou, Y. Q., Feng, Y. L., Shoeib, M., \& Harnew, T. (2008). Identification and determination of hexachlorocyclopentadienyl-dibromocyclooctane (HCDBCO) in residential indoor air and dust: A previously unreported halogenated flame retardant in the environment. Environmental Science and Technology, 42(2), 386-391. 